\title{
ATAQUE TRANSICIONAL COMO TÉCNICA DE COMBATE A INCÊNDIOS EM EDIFICAÇÕES: UMA REVISÃO DA LITERATURA
}

Wesley Aparecido Ronqui ${ }^{1}$

\section{RESUMO}

Este trabalho objetivou analisar como o Ataque Transicional (AT) pode ser utilizado por bombeiros em situações de incêndios estruturais. O AT é uma técnica na qual preliminarmente um ataque externo ofensivo é direcionado para o interior de uma edificação com o intuito de abrandar a agressividade de um incêndio e melhorar as condições internas para que na sequência outras equipes possam adentrar e continuar o combate realizando demais atividades pertinentes. Nesse sentido, este trabalho se justifica como relevante tendo em vista que o profissional do bombeiro deve ter conhecimento acerca das técnicas de combate a incêndios, pois poderá desempenhar suas habilidades de maneira mais eficaz. A metodologia foi baseada numa pesquisa qualitativa de análise bibliográfica em artigos online e periódicos científicos. Das análises dos estudos encontrados pode-se concluir que o AT, desde que utilizado dentro de critérios operacionais adequados, pode ser tido como uma opção viável de combate a incêndio estrutural.

Palavras-chave: Ataque transacional; Combate a incêndio; Incêndio estrutural.

1 Segundo Sargento do Corpo de Bombeiros Militar do Estado do Paraná. E-mail: wesleyronqui01@gmail.com 


\title{
TRANSITIONAL ATTACK AS A FIRE FIGHTING TECHNIQUE IN BUILDINGS: A LITERATURE REVIEW
}

\begin{abstract}
This work aimed to analyze how the Transitional Attack (AT) can be used by firefighters in situations of structural fires. AT is a technique in which preliminarily an offensive external attack is directed to the interior of a building in order to slow down the aggressiveness of a fire and improve the internal conditions so that, in the sequence, other teams can enter and continue the combat carrying out other activities pertinent. In this sense, this work is justified as relevant considering that the firefighter's professional must have knowledge about fire-fighting techniques, as he will be able to perform his skills more effectively. The methodology was based on a qualitative research of bibliographical analysis in online articles and scientific journals. From the analysis of the studies found, it can be concluded that the TA, provided it is used within adequate operational criteria, can be seen as a viable option for fighting structural fire.
\end{abstract}

Keywords: Transactional attack. Fighting a fire. Structural fire.

Artigo Recebido em 28/03/2020 e Aceito em 30/08/2021 


\section{INTRODUÇÃO}

Presente praticamente em todo o globo terrestre, os bombeiros, enfrentam diuturnamente incêndios de todas as magnitudes. A prevenção ainda é a melhor maneira para se evitar danos e prejuízos advinda de incêndios, porém conhecer o comportamento do fogo e dominar as táticas e técnicas para supressão de um incêndio é de suma importância para os profissionais do bombeiros.

A atividade de combate a incêndio, em geral possui regramentos doutrinários através de manuais, livros, artigos, procedimentos operacionais, os quais ditam qual a melhor forma de atingir os melhores resultados com menores riscos aos combatentes e às vítimas, além de visar também não piorar as condições do patrimônio (CBMGO, 2016). Por isso, manter-se atualizado, enquanto bombeiro, fará com que a "missão" seja sempre desempenhada da melhor forma.

Em recentes estudos, nota-se que houve algumas mudanças na configuração dos incêndios atuais em comparação aos de décadas anteriores. As construções, seus materiais de acabamento e revestimento, bem como as mobílias vêm apresentando materiais químicos diferentes aos quais os bombeiros estavam acostumados a lidar anteriormente, logo, o comportamento dos incêndios se modificou consequentemente (NORWOOD and SALAMEH, 2018).

Frente às mudanças percebidas, os institutos de pesquisas $e$ organizações de serviço de bombeiros vêm buscando inovações em técnicas e equipamentos com o intuito de melhorar a segurança do bombeiro e a eficácia no combate a incêndio. Como resultado de algumas dessas inovações desenvolveu-se uma técnica denominada Ataque Transicional (AT) ou também conhecida como Ataque de Transição. 
A filosofia do AT é fornecer água remotamente a partir de uma posição externa - porta da frente, janela, quintal etc. - de uma estrutura a fim de diminuir a agressividade das chamas em seu interior para que na sequência outras equipes possam adentrar a edificação e atacar outros focos, resgatar vítimas e realizar outras atividades pertinentes (SMITH, 2017).

Realizar um ataque ofensivo externo e depois adentrar na edificação não é algo novo, muitos bombeiros ao longo de sua carreira provavelmente já 0 fizeram em algum momento, porém diante de algumas controvérsias sobre tal técnica, faz jus um aprofundamento de seus fundamentos. Tratando-se de um tema desconhecido por muitos no âmbito nacional, decidiu-se por desenvolver este artigo objetivando buscar informações a respeito desta técnica e analisar suas características e sua aplicabilidade na atividade de combate a incêndio estrutural.

Para a obtenção dos dados se utilizou da pesquisa qualitativa de análise bibliográfica em artigos online e periódicos científicos, cuja análise se mostrou bastante complexa, uma vez que a maioria dos trabalhos científicos acerca de tal tema é escassa ou se apresentam em outros idiomas. Através de revistas online foi possível o acesso a artigos e experimentos realizados, em especial, nos Estados Unidos da América.

No que concerne os resultados práticos sobre o AT, o presente artigo muito se baseou no National Institute of Standards and Technology (NIST) e o Underwriters Laboratories (UL), os quais vêm buscando aprimorar o conhecimento em pesquisa de incêndios e desenvolvendo educação prática e avançada para bombeiros.

\section{ATAQUE TRANSACIONAL (AT)}




\section{Nos manuais de combate a incêndios comumente encontramos} descritos nas técnicas de combate a incêndio estrutural/urbano alguns tipos de ataque, tais como: ataque direto, ataque indireto, combinado, tridimensional entre outros.

O AT se enquadra também como uma das técnicas de combate consistindo na aplicação de um jato compacto de água de fora para dentro da edificação, mirando um alvo estático, no teto de um cômodo em que seja visível o incêndio na fase denominada Totalmente Desenvolvido (LAMBERT, 2014).

O AT foi uma técnica de combate a incêndio do passado que está em voga novamente. A referida técnica foi usada por muitos anos até meados da década de 1980, quando várias publicações e livros enfatizaram que aplicações fluxos externos de água para o interior de edificações resultam em "empurrar fogo" por toda a estrutura (SMITH, 2017). Após os anos de 80, as orientações eram de se evitar aplicar água em um incêndio do exterior da estrutura, pois isso poderia acarretar numa série de consequências, tais como aumentar o perímetro incendiado, a não visualização do foco do incêndio, desperdício de água, encharcamento de materiais, com prejuízo da técnica de salvatagem, piora da atmosfera respirável para possíveis vítimas entre outras.

O AT foi introduzido nos Estados Unidos da América, novamente nos últimos anos por muitos instrutores internacionais credíveis como um método alternativo de ataque de incêndio na esperança de reduzir ferimentos de bombeiros ou mortes por comportamento extremo do fogo (SMITH, 2017).

Sendo assim, o AT é tido como um instrumento alternativo no desempenho profissional do bombeiro, pois se trata de uma técnica plausível de efetividade em determinados incêndios, porém as características do incêndio é o que determina o uso da técnica adequada pelo profissional. Segundo Smith (2017) o grande equívoco é pensar que o AT substituirá um ataque de incêndio interno comum, na verdade um incêndio envolve diversos 
Revista Científica do Corpo de Bombeiros Militar de Pernambuco

Artigo Publicado no Vol.07 N.19 - Julho a Dezembro 2021 - ISSN 2359-4829

Versão on-line disponível em: http://www.revistaflammae.com

aspectos e decisões, devendo cada método de ataque ser escolhido de acordo com cada situação.

Sendo assim, o esta técnica objetiva reduzir a temperatura do ambiente incendiado, através de um ataque externo que suaviza a situação do incêndio, possibilitando uma transição para a parte interna em um cenário de incêndio já enfraquecido pelo jato aplicado externamente. Para ser empregada, o chefe de linha deve ser capaz de ver o ambiente com incêndio na fase Totalmente Desenvolvido (CBMMG, 2020).

Em 2014 a National Fire Protection Association (NFPA) definiu o AT como sendo um ataque ofensivo iniciado por uma operação de linha de mão externa indireta, no compartimento do incêndio, para iniciar o resfriamento durante a transição para o ataque de fogo direto no interior, em coordenação com as operações de ventilação.

Figura 01 - Modelo do tipo ataque ofensivo externo (indireto), cujo poderá evoluir para um ataque interior (direto) e assim configurar-se no ataque transicional.

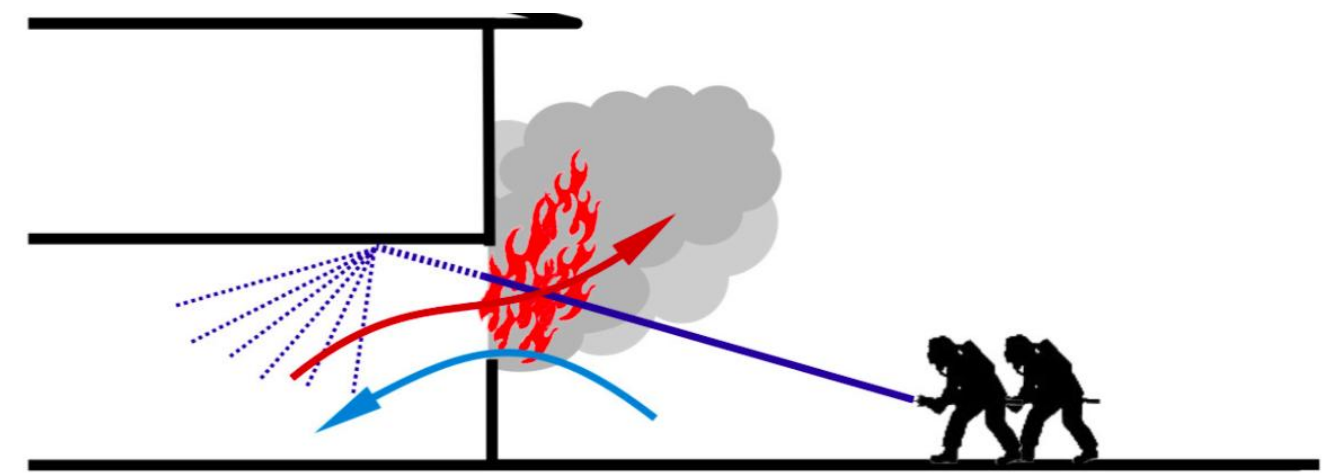

Fonte: Arnalich, 2015, pág 02.

Esse ataque de origem externa, demonstrado na Figura 01, é a aplicação de água do lado de fora para o interior da sala de queima, com o 
objetivo de "suavizar" as condições internas, reduzindo o poder de fogo (taxa de liberação de calor). Um fluxo compacto de água entra através de uma janela na área do fogo, atingindo o teto e se desintegrando em pequenas gotas que caem no fogo (ARNALICH, 2016).

\subsection{MUDANÇAS NO COMPORTAMENTO DOS INCÊNDIOS}

Historicamente, o principal meio de desenvolver estratégias e táticas de combate a incêndios foi baseado nas observações e experiências dos bombeiros. Tais observações e experiências nos forneceram ferramentas valiosas para combater de modo mais técnico os incêndios. No entanto, as técnicas baseadas na experiência não fornecem os meios para medir $\mathrm{e}$ compreender totalmente a progressão atual do fogo e o impacto de cada ação tomada em uma cena de incêndio. Devido a esses limites, às vezes tira-se conclusões imprecisas podendo resultar em cursos de ação ineficazes e contraproducentes (SCHOTTKE, 2016).

Além disso, mudanças estão ocorrendo nas características construtivas das edificações, nos materiais de acabamento/revestimento, bem como nos mobiliários, os quais, cada vez mais estão sendo utilizados como matéria prima produtos à base de petróleo e outros materiais altamente desfavoráveis a uma situação de incêndio. Os incêndios atuais liberam energia mais rapidamente, atingem o potencial de flashover ${ }^{2}$ mais cedo, podendo atingir temperaturas mais altas do que incêndios comumente enfrentados há alguns anos atrás, além da toxicidade na fumaça que está piorando devido a composição química dos materiais modernos (SCHOTTKE, 2016).

Frente a este cenário, percebe-se que as especificidades dos incêndios foram modificadas, os materiais de queima são diferentes devido ao processo de modernização das edificações e tecnologias da construção civil. Para

\footnotetext{
${ }^{2}$ Ignição súbita generalizada
} 
Norwood e Salameh (2018) embora tivesse havido concentração em soluções alternativas que foram permitidas operar em um ambiente mais hostil, com melhores equipamentos tais como mangueiras, esguichos, equipamentos de proteção individual (EPI) coletiva (EPC) e equipamentos de proteção respiratória (EPR), há ainda certa deficiência no entendimento das mudanças do comportamento dos incêndios modernos, bem como na identificação de melhores táticas e técnicas para combatê-los mais efetivamente. Tais pesquisadores apontam que os estudos atuais da ciência do fogo estão tentando mitigar essa lacuna entre o serviço de bombeiros e a compreensão da dinâmica moderna do fogo - uma compreensão que é essencial para o sucesso profissional dos bombeiros.

Nesse sentido, a ciência do fogo e seu comportamento num incêndio devem ser encarados como uma necessidade real dos profissionais do bombeiro compreender, tendo em vista sua aplicabilidade cotidiana, segundo Schottke (2016, p. 01) a respeito dessas mudanças e a importância de se entender seus impactos:

\footnotetext{
Recentemente, devido a essas pesquisas têm-se experimentado grandes mudanças em nossa compreensão do comportamento básico do fogo e das táticas usadas para atacar incêndios. Não entender o impacto dessas mudanças, pode colocar os profissionais em posições que são tão inseguras que pode impedi-los de cumprir nossa missão de preservar a vida e a propriedade.
}

Com isso, é possível compreender que os incêndios são situações adversas, em que o profissional do bombeiro se esbarra em diversos cenários, com diferentes problemáticas, cada uma com especificidades intrínsecas que não podem ser tratadas, nem encaradas de modo igual. Há de se concluir que cada incêndio contempla um espaço, estrutura, materiais, resíduos e vítimas de modos diferentes, não podendo ser encarado da mesma forma, ou mesmo ter iguais intervenções profissionais, é preciso compreender a ciência do fogo e sua aplicação para que o profissional esteja adequado e capacitado a agir da 
melhor forma. Dessa maneira, o AT se mostra como uma alternativa eficaz para determinadas situações de incêndios, em que o profissional do bombeiro poderá atuar de modo a melhor desempenhar seu trabalho de salvar vidas e esperanças.

\subsection{APLICAÇÕES DO ATAQUE TRANSICIONAL}

Geralmente, táticas de ataque externas, nas quais a água é lançada de uma posição externa para as instalações internas, são consideradas um recurso de combate a incêndio simples e não muito efetivo, porém torna muito prudente e vantajosa quando a entrada à edificação não é possível ou não é recomendado devido à falta de segurança estrutural. Também é normalmente usado como uma tática quando os recursos não são suficientes, quando o suprimento de água é limitado ou a informação disponível sobre o incidente é confusa e é conveniente agir com cautela até que uma avaliação melhor da situação possa ser feita (ARNALICH, 2016).

As vantagens básicas do ataque inicialmente externo são claras para qualquer pessoa no solo: a água pode ser lançada de uma posição segura e desde o início, enquanto a informação é coletada, mais recursos chegam ou enquanto um plano de ação é projetado (ARNALICH, 2016).

Schottke (2016) com auxílio de colaboradores escreveram o "Evidencebased practices for strategic and tactical firefighting", estudo no qual se compilou dados de pesquisas dos últimos 15 anos do National Institute of Standards and Technology (NIST) e o Underwriters Laboratories (UL) assistidos pelos departamentos de bombeiros de Nova York (FDNY) e Chicago (CFD), no qual realizaram cenários de incêndio controlado em laboratórios especialmente construídos em edificações residências vagas, ou seja sem uso. 
Os pesquisadores desses laboratórios usaram uma variedade de instrumentos para medir temperaturas em toda a estrutura, em várias alturas dentro de cada sala, as taxas de liberação de calor gerada a partir do conteúdo das salas, a velocidade e a direção das chamas no compartimento incendiado e dos pontos de ventilação. Estas experiências mostraram que um ataque ofensivo externo - introduzindo água do lado de fora - poderia reduzir temperaturas em outras partes da estrutura, mesmo quando aplicado a alguma distância do fogo, obviamente não extinguindo completamente as chamas, mas, desacelerando o crescimento do incêndio, esfriando enormes quantidades de combustível gasoso quente e combustível sólido (SCHOTTKE, 2016).

Constatou-se que o efeito deste ataque exterior ofensivo ou AT é significativo, mas de curta duração. Para evitar que o fogo recuperasse o seu estado anterior, seria necessário entrar na edificação o quanto antes, para dar continuidade às demais ingerências. Conforme Shottke (2016) este ataque combinado seria mais seguro para os bombeiros porque ao adentrar, a temperatura interna seria mais baixa e a visibilidade aumentada.

Para Lambert (2014), após o primeiro ataque - externo - a temperatura no compartimento tenderia a baixar consideravelmente, criando melhores condições de trabalho. Neste momento seria preciso executar um ataque interior, caso contrário o incêndio poderá crescer novamente, perdendo todo o trabalho inicialmente efetuado. Abaixo na Figura 02, o gráfico melhor representa o possível cenário de um AT, nas condições supracitadas. 
Revista Científica do Corpo de Bombeiros Militar de Pernambuco

Artigo Publicado no Vol.07 N.19 - Julho a Dezembro 2021 - ISSN 2359-4829

Versão on-line disponível em: http://www.revistaflammae.com

Figura 02 - Curva de calor de um incêndio num compartimento ventilado.

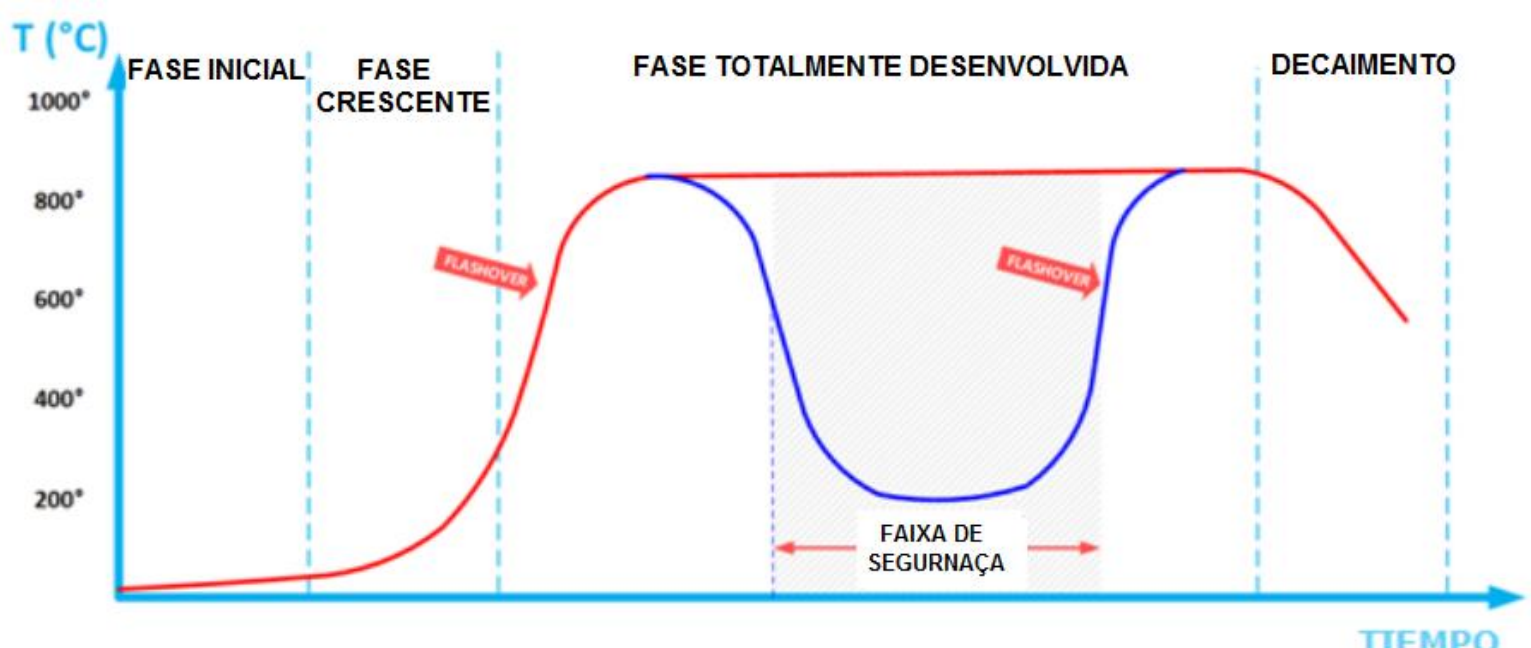

Fonte: Lambert, 2014.

Legenda: Curva de calor de um incêndio num compartimento ventilado. é indicada pela linha vermelha. $O$ efeito de um ataque exterior é indicado em azul. Depois de um ataque exterior, 0 incêndio retardará 0 seu progresso. 0 período de tempo entre 0 apaziguamento e o segundo levante pode ser utilizado para entrar e extinguir completamente o incêndio

\subsection{CONSEQUÊNCIAS À EXPOSIÇÃO DO BOMBEIRO}

Há muitos indícios de que toxicidade em um incêndio está piorando com os materiais modernos. Devido a isso, pesquisas foram realizadas nesse âmbito a fim de entender melhor esse cenário. $\mathrm{O}$ artigo intitulado "Impact of Fire Suit Ensembles on Firefighter PAH Exposures as Assessed by Skin Deposition and Urinary Biomarkers" dos autores Wingfors et al. (2018), em um estudo constatou que determinadas substâncias oriundas da combustão podem além de ficar depositadas sobre o equipamento de proteção, também penetrar agressivamente nas camadas protetoras do mesmo, sendo absorvidas pelo organismo do bombeiro, podendo trazer como consequências desde alterações fisiológicas mínimas a danos mais severos saúde. 
Conforme Fent et al. (2020) outro estudo, denominado "Firefighters absorption of PAHs and VOCs during controlled residential fires by job assignment and fire attack tactic", foi monitorado o metabolismo de um grupo de bombeiros (respiração e urina) que combateram incêndios residenciais controlados e examinaram os resultados por atribuição de trabalho (ventilação, ataque, busca de vítimas) e tática de ataque a incêndio. Os resultados apontaram que não houve redução no nível de toxicidade dentro da estrutura ao comparar ataque transicional ao interior ataque. No entanto, as concentrações medianas de metabólitos tais como hidrocarbonetos aromáticos policíclicos (HPAs) na urina e as concentrações medianas da respiração expirada do benzeno e demais compostos - pireno, fenantreno e fluoreno aumentaram consideravelmente para aqueles envolvidos em tarefas de maior proximidade às chamas e fumaça (FENT et al. 2020). Algumas dessas substâncias, pelo contato dérmico prolongado trazem indícios carcinogênicos em humanos (CETESB, 2018).

Diante disso, ainda em seu estudo, Fent et. al. (2020) afirma que quando expostos a altas temperaturas e fumaça pesada, nossa temperatura corporal aumenta. Consequentemente, o aumento da temperatura corporal dos bombeiros fará com que suem mais profusamente e que a taxa de absorção aumenta quando exposta àquele ambiente tóxico.

Face aos dois artigos supracitados, entende-se que mesmo com a utilização de proteção adequada (EPI e EPR), o bombeiro quando exposto a um ambiente desfavorável - temperatura elevada e fumaça tóxica - pode absorver substâncias nocivas ao seu organismo, além de sofrer desgastes inerentes a atividade. Por isso Fent et al. enfatiza a importância de utilizar, quando possível, o AT haja vista a menor exigência de exposição do combatente. 


\subsection{PRINCIPAIS RESULTADOS DO NIST, UL E COLABORADORES}

Em consonância com o resultado das pesquisas e com o advento das manifestações dos incêndios modernos em seus índices de toxicidade e malefícios à saúde humana, presume-se que hoje não se tem o mesmo tempo de supressão de um incêndio de épocas remotas, devido à velocidade de propagação e desenvolvimento do fogo nos materiais modernos. Desse modo, o AT representa uma opção a ser considerada, pois pode permitir que as ações sejam mais rápidas, seguras e com melhor visibilidade. Das pesquisas do NIST e o UL, assistidos pelos departamentos de bombeiros, concluíram que o AT aumenta a possibilidade de sobrevivência das vítimas, diminui a temperatura e a produção de gases tóxicos, além de melhorar as condições das vítimas no interior da estrutura (SCHOTTKE, 2016).

Segundo Schottke (2016) alguns pontos principais de tais pesquisas, a respeito do AT, devem ser tomados como importantes nos incêndios: o ataque externo para o interior da edificação não vai fazer com que o fogo seja espalhado para todo o ambiente; a água deve ter fluxo direto com permanência de 10 (dez) a 20 (vinte) segundos no teto do compartimento; uma vazão entre 200 e 500 litros por minuto deverá ser suficiente, dependendo de cada caso.

O Ataque Transicional permite que os gases aquecidos sejam expulsos do ambiente e que os combustíveis sejam resfriados, porém para que isso ocorra deve-se: evitar o ataque externo com jatos do tipo nevoeiro, neblina e atomizado, pois estes tipos de jato impedem a saída dos gases quentes e aquecidos; a aplicação do fluxo de água pela janela ou porta melhorou as condições internas do ambiente; a aplicação de fluxo imediato de água suprimiu o fogo mais rapidamente; tal técnica deve preceder a entrada no compartimento, busca ventilação e tática; é preciso começar de fora, mas terminá-lo dentro; e por fim, a coordenação do fogo com ventilação vertical deve pospor o Ataque Transicional (SCHOTTKE, 2016). 
Dessa forma, este método de combate incêndio representa uma possibilidade que adequa agilidade e segurança dos profissionais do bombeiro, por se tratar de uma técnica primeiramente externa, que diminui os riscos por toxicidade e acidentes destes profissionais e num segundo momento, interna, que promovendo a entrada rápida no ambiente sem que haja alastre do fogo ou cause mais danos materiais nos compartimentos do ambiente. Sendo assim, o uso de tal técnica deve ser abordado como uma das formas do combate a incêndios, em que o profissional poderá adequar sua tática a depender do tipo de situação enfrentada, sendo necessária a formação técnica e capacitação para situações adversas.

\subsection{ATAQUE TRANSICIONAL: APLICAÇÃO PRÁTICA E TEÓRICA}

\subsubsection{Ataque Transicional e ventilação - visão prática}

Em seu recente artigo "Combining transitional attack and early ventilation to reduce toxic exposures" publicado em março de 2020 na revista Fire Rescue 1, Kevin Maschue defende a combinação de ataques transicionais com ventilação precoce. Trata-se do vice-chefe de planejamento e pesquisa do Departamento Médico e de Bombeiros de Mesa (Arizona), com 32 anos no serviço de bombeiros, possui uma vasta experiência que varia de bombeiro, engenheiro, paramédico e capitão, e conta com certificações de equipes especiais para materiais perigosos e resgate técnico.

Conforme Maschue (2020), que há cinco anos teve acesso aos estudos do UL FSRI, Instituto Nacional de Padrões e Tecnologia (NIST) e do Bureau de Álcool, Tabaco, Armas de Fogo e Explosivos (ATF), acabou percebendo que conceitos de taxas modernas de queima de incêndio, aumentos de toxicidade, perigos de flashover estavam provando as razões pelas quais as taxas de óbito 
em serviço estavam aumentando enquanto o número de incêndios, na época, estava diminuindo e por isso exigiam abordagens técnicas mais eficientes.

A partir desse momento, através de um comitê decidiram ensinar as técnicas do AT, inicialmente à 400 bombeiros. Quatro anos depois, ao instituir essa abordagem de combate a incêndios, além de implementar uma avaliação de 360 graus da estrutura antes da entrada, que também foi recomendada, o autor diz ter alcançado o objetivo de melhorar a segurança dos bombeiros.

\begin{abstract}
Sem dúvida, reduzimos as circunstâncias que levavam a situações de quase acidente e óbitos em serviço. Em quatro anos, não ouvi falar de uma condição de comportamentos extremos do fogo e revisei muitos dos incêndios em funcionamento de nossos departamentos como parte de um programa de garantia de qualidade. Também deixamos de perder uma quantidade enorme de propriedades, pois não me lembro da última vez em que ficamos na defensiva em um incêndio, e não há dúvida de que esses métodos nos deram a oportunidade de resgatar vítimas com mais sucesso e viável quando a situação se apresentou (Maschue, 2020, p. 02).
\end{abstract}

Para o articulista o AT, combinado com técnicas de ventilação precoce, pode auxiliar o bombeiros de duas principais formas. Primeiro, na redução da exposição dos bombeiros à atmosferas tóxicas e cancerígenas e segundo pelo menor risco de ocorrência de acidentes e mortes pelo comportamento agressivo do fogo, abalos estruturais entre outros.

O fato é que o AT é uma matéria que não deve ser ignorada. Independentemente de seu inter-relacionamento com outras técnicas ventilação, por exemplo - o AT deve ser objeto de estudo e discutido por profissionais da área, pois recentes pesquisas estão demonstrando os resultados aceitáveis para tal abordagem técnica.

\title{
2.4.2 Ataque Transicional - visão teórica
}

No artigo intitulado "Ataque de Transição", Karel Lambert descreve uma situação real, em que profissionais do departamento de Bombeiros de 
Moeskroen - Bélgica - foram alertados para um incêndio numa habitação e se deslocam para o local, no ano de 2010. Karel Lambert é chefe de batalhão do Corpo de Bombeiros de Bruxelas. Ele é um instrutor reconhecido internacionalmente e participou de programas de treinamento em 14 países. Lambert possui mestrado em engenharia civil, segurança e saúde ocupacional e engenharia de segurança contra incêndio. Ele também é professor convidado na Universidade de Ghent, além de co-autor de dois livros e escreveu vários artigos sobre combate a incêndios.

Chegando ao local, se deparam com uma residência de 5 a 6 metros de fachada, com uma janela grande e uma porta de entrada, sem acesso a parte dos fundos. O incêndio estava apresentando chamas através da janela e muita fumaça no corredor de acesso. De acordo com informações obtidas não havia vítimas no interior.

Com cerca de dois minutos a equipe havia estabelecido linhas em coil ("sistema Cleveland"), adentraram pela porta da frente utilizando-se da técnica 3DWF - que consiste em aplicação de pulsos, jatos atomizados resfriamento da camada térmica - e progrediram três metros até alcançarem a porta do compartimento incendiado, onde na sequência realizaram um ataque massivo utilizando-se os padrões "O" e "Z" sobre as chamas, extinguindo-as, num total de tempo de aproximadamente três minutos.

Fazendo uma reflexão sobre a técnica aplicada, que por sua vez foi muito bem executada e obtiveram bons resultados Lambert vai além. $O$ articulista pensou teoricamente em outra possibilidade de incêndio de mesmas proporções, com a diferença que ao invés de progredir três metros, os bombeiros tivessem que progredir oito metros. É provável que o tempo gasto seria maior, as temperaturas aumentariam e riscos também, inclusive de morte, para os bombeiros e possíveis vítimas.

Aplicando-se os princípios do AT, nesta situação hipotética, Lambert (2014) menciona que os riscos poderiam ser menores, pois se aplicando inicialmente um ataque externo para 0 interior da edificação, não muito 
prolongado, poderia suavizar as chamas, diminuiria a temperatura e a exposição dos profissionais, tornaria a camada de gases menos inflamável, em que acarretaria melhores condições para posterior ataque interno e realização das demais atividades (LAMBERT, 2014).

Levando em consideração que cada situação envolve tomada de decisões diferentes em uma ocorrência, Lambert (2014) finaliza seu artigo enfatizando que os responsáveis hierárquicos devem optar pela melhor forma de atuação de acordo com o cenário encontrado e com os recursos disponíveis.

\section{CONCLUSÕES}

A partir da análise teórica foi possível concluir que o Ataque Transicional é adequado no combate a incêndios estruturais modernos, pois melhora a visibilidade, diminui a temperatura e o excesso de gases tóxicos e limita a propagação externa das chamas para outras edificações. Essas vantagens contribuem diretamente em melhores condições de sobrevivência às vítimas e aos profissionais do bombeiro, que ficam expostos a gases tóxicos e situações de risco. Além disso, o AT retarda a progressão do incêndio sem afetar negativamente o equilíbrio térmico ou "empurrar" gases e fumaças aquecidas para áreas não atingidas, desde que seja evitada a aplicação de água pulverizada/neblinada, pois isso poderá bloquear a saída de gases, causando desequilíbrio térmico, recomenda-se assim, a aplicação de jato sólido. Portanto, o Ataque Transacional deve preferencialmente ser implementado em momentos em que a entrada do bombeiro ao interior da edificação seja impedida pelo incêndio ou exponha o profissional em demasia a altas temperaturas, fumaça tóxica, riscos estruturais entre outros. É preciso o domínio de técnicas atualizadas e equipamentos adequados na aplicação do 
Revista Científica do Corpo de Bombeiros Militar de Pernambuco

Artigo Publicado no Vol.07 N.19 - Julho a Dezembro 2021 - ISSN 2359-4829

Versão on-line disponível em: http://www.revistaflammae.com

AT e, o principal, a prevenção sendo levada a sério, dessa forma, menor serão os prejuízos ao patrimônio e à vida humana.

\section{REFERÊNCIAS}

ARNALICH, Art. Comprendiendo El Ataque Ofensivo Exterior. Artículo original publicado enChina Fire Bulletin, edición Otoño de 2016. Disponível em: <http://www.fundamentosparabomberos.es/publicaciones/articulos/311comprendiendo-el-ataque-ofensivo-exterior> Acessado em 20 de julho de 2019.

CBMGO. Manual De Fundamentos de Combate a Incêndio Corpo de Bombeiros Militar do Estado De Goiás. 1를 Edição 2016 Corpo de Bombeiros Militar do Estado de Goiás. 2016. Disponível em:

$<$ https://www.bombeiros.go.gov.br/wpcontent/uploads/2015/12/cbmgo1aedicao 20160921.pdf>. Acessado em 16 de julho de 2020.

CETESB. HPAs - Hidrocarbonetos Policíclicos Aromáticos. Ficha de informação toxicológica. Divisão de Toxicologia Humana e Saúde Ambiental. 2018.

Disponível em:

$<$ https://cetesb.sp.gov.br/laboratorios/wpcontent/uploads/sites/24/2018/07/HPA sHidrocarbonetos-Polic\%C3\%ADclicosArom\%C3\%A1ticos.pdf>. Acessado em 22 de julho de 2020.

FENT, K.W., TOENNIS, C., SAMMONS, D. et al. Firefighters' absorption of PAHs and VOCs during controlled residential fires by job assignment and fire attack tactic. J Expo Sci Environ Epidemiol 30, 338-349 (2020).

Disponível em: <https://doi.org/10.1038/s41370-019-0145-2>. Acessado em 19 de julho de 2020.

KERPER, S., REGAN, J.W., HORN, G.P. et al. Effect of Firefighting Intervention on Occupant Tenability during a Residential Fire. Fire Technol 55, 2289-2316 (2019). Disponível em:

<https://doi.org/10.1007/s10694-019-00864-2>. Acessado em 21 de julho de 2020.

LAMBERT, Karel. Transitional attack. CFBT-BE. 2014. Disponível em: <http://www.cfbt-be.com/images/artikelen/artikel_21_ENG.pdf> Acessado em 10 de julho de 2019. 
Revista Científica do Corpo de Bombeiros Militar de Pernambuco

Artigo Publicado no Vol.07 N.19 - Julho a Dezembro 2021 - ISSN 2359-4829

Versão on-line disponível em: http://www.revistaflammae.com

NFPA - National Fire Protection Association. 2019. Disponível em: <https://www.nfpa.org/-/media/Files/Membership/member-sections/MetroChiefs/Urban-Fire-Forum/2014/CFDTransitionalAttackDefinition.ashx?la=en> acessado em 31 de julho de 2019.

NORWOOD P. J.; Nick J. SALAMEH. Today's Evolving Fire Attack. Fire Engineering Magazine. 2018. Disponívbel em:

$<$ https://www.fireengineering.com/articles/2018/09/todays-evolving-fireattack.html>. Acessado em 08 de julho de 2019.

SCHOTTKE, David. Evidence-Based Practices for Strategic And Tactical Fire fighting. International Association of Fire Chiefs, National Fire Protection Association. Ed. JonesandBartlettlearningpages cm ISBN 978-1-284-08410-8 1. Fire extinction. 2. Fire prevention. I. International Association of Fire Chiefs. II. National Fire Protection Association. 2016.

SMITH, Trey. Fire Physics the New Offensive Fire Attack. Carolina fire journal. 2017, pág. 01 a 10). Disponível em:

$<$ https://www.carolinafirejournal.com/Articles/ArticleDetail/Articleld/6385/Fire-

Physics-The-New-Offensive-Fire-Attack acessado em 18/07/2020>. Acessado em 22 de julho de 2020.

WINGFORS, Håkan; NYHOLM, Jenny Rattfelt, MAGNUSSON, Roger, WIJKMARK, Cecilia Hammar. Impact of Fire Suit Ensembles on Firefighter PAH Exposures as Assessed by Skin Deposition and Urinary

Biomarkers. Annals of Work Exposures and Health, Volume 62, Issue 2, March 2018, Pages 221-231.Disponível em:

<https://doi.org/10.1093/annweh/wxx097>. Acessado em 20 de julho de 2020. 